\title{
In memoriam Carlton Skinner (1913-2004)
}

\section{Christian Coiffier}

\section{Q OpenEdition}

\section{Journals}

\section{Édition électronique}

URL : http://journals.openedition.org/jso/1105

DOI : 10.4000/jso.1105

ISSN : $1760-7256$

Éditeur

Société des océanistes

\section{Édition imprimée}

Date de publication : 1 décembre 2006

Pagination : 223-224

ISSN : 0300-953x

\section{Référence électronique}

Christian Coiffier, «In memoriam Carlton Skinner (1913-2004)», Journal de la Société des Océanistes

[En ligne], 122-123 | Année 2006, mis en ligne le 08 avril 2008, consulté le 15 septembre 2020. URL http://journals.openedition.org/jso/1105 


\section{ACTUALITÉS}

\author{
In memoriam \\ Carlton Skinner (1913-2004)
}

par

Christian COIFFIER

Carlton Skinner est né en 1913 à Boston, Back Bay, où il a grandi; son père était professeur à l'université d'Harvard et sa mère titulaire d'un Ph.D de Radcliff, le Harvard féminin d'alors. Son adolescence se déroule en NouvelleAngleterre, puis, après des études secondaire à Tilton, dans le New Hamphire, il obtient un diplôme de l'université Wesleyan dans le Connecticut et complète sa formation dans les finances à l'université de Californie à Los Angeles. Il commence ensuite sa carrière comme officier de Marine dans l'us Navy. En 1943, alors qu'il commande en tant que lieutenant le gardecôte Sea Cloud dans l'Atlantique nord, il obtient de sa hiérarchie l'autorisation d'effectuer la première expérience d'une complète déségrégation dans la Marine américaine. Il renouvelle cette expérience, en 1944, sur la frégate Hoquiam sur les côtes des îles aléoutiennes. La réussite de ces actions pour l'égalité des citoyens américains le fait engager, en 1948, dans le Human Rights Program du président Harry S. Truman pour rédiger l'Organic Act qui demeure actuellement la constitution du territoire de Guam. Le 17 septembre 1949, le président Truman le nomme premier gouverneur civil de Guam pour établir une transition avec le précédent gouvernement militaire. Il demeure à ce poste jusqu'en 1953, alors qu'il avait à peine quarante ans. Il crée le Territorial College of Guam, l'actuelle université de Guam, pour permettre aux étudiants issus de familles à revenus modestes d'avoir accès, dans leur propre île, à une éducation supérieure.

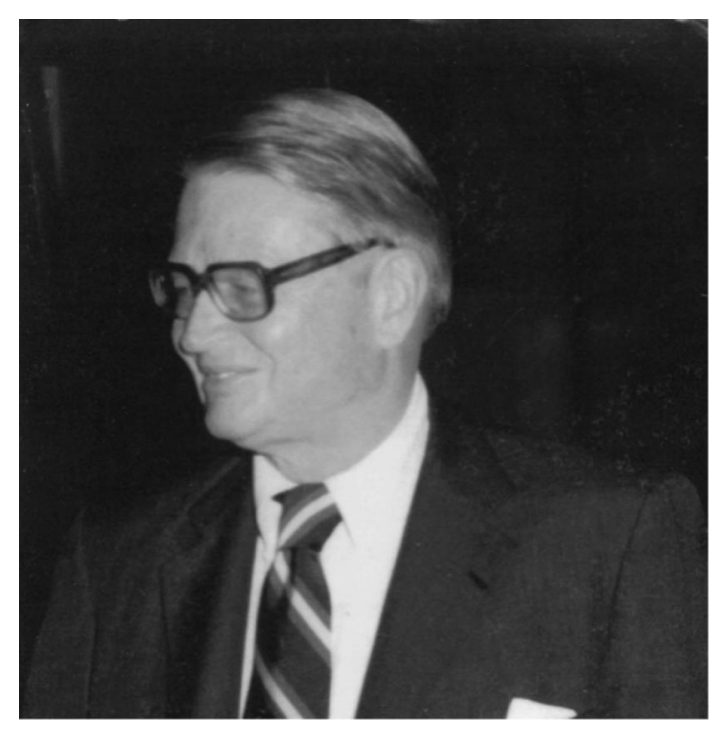

Il encourage également la mise en place d'un système Duty Free qui stimule l'économie de l'île pour en faire l'une des plus florissantes du Pacifique. Il aura ainsi été le dernier gouverneur militaire, officier de Marine et le premier gouverneur civil dépendant du ministère de l'Intérieur. C'est à ce titre que la Skinner Plaza dans la capitale Hagatna honore le souvenir du nom de celui qui fut appelé le "George Washington of Guam » (Merto, 2004). Carlton Skinner fut successivement président de la Banque de Guam, éditeur du Guam Daily News et fondateur de la compagnie Air Micronesia. Il travailla ensuite pour diverses compagnies financières à New York et à San Francisco.

Le gouverneur Carlton Skinner était tout aussi connu dans le Pacifique anglophone que francophone. Il fut en effet nommé par le président John F. Kennedy comme premier secrétaire des États-Unis à la Commission du Pacifique Sud. Il fut reconduit sept fois dans ce poste. C'est à cette époque, en 1970, qu'il se remaria avec une anthropologue française, Solange Petit. Il lia alors au cours de réunions périodiques à Nouméa des liens étroits avec les représentants français du Pacifique tout comme avec les leaders locaux des territoires d'Océanie. Parmi ces derniers, le président de Nauru, les présidents et gouverneurs des États de Micronésie, Francis Bogotu des îles Salomon et Jean-Marie Tjibaou. C'est dans ce cadre qu'il conseilla les responsables de la plupart des nouveaux États du Pacifique pour l'accession de leur pays à l'indépen- 
dance. Ratu Mara, Premier ministre des Fidji, disait de Carlton Skinner : "C'est un homme de conviction et non d'ambition ». Il fut en effet toujours prompt à susciter le choix de ressortissants des États du Pacifique pour occuper des postes de responsabilités dans les institutions régionales et internationales. C'est ainsi, sur sa proposition, qu'en octobre 1969 fut nommé, comme premier secrétaire de la Commission du Pacifique Sud originaire d'un État du Pacifique, Harris Moor des Samoa occidentales.

Carlton Skinner appartint quelques années à la Société des Océanistes où il fit une conférence remarquée sur les États du Pacifique qu'il nommait le «Quatrième monde ». Il publia en 1997 un ouvrage intitulé After Three Centuries: Representative Democraty and a Civilian Government for Guam. Cet homme, d'une rare sensibi-

\section{Hommage à Bernard Juillerat}

Nous venons d'apprendre, avant de mettre sous presse ce numéro, le décès de notre collègue Bernard Juillerat survenu le mardi 6 juin, à la suite d'une longue maladie. Ses obsèques ont eu lieu le lundi 12 juin au crématorium du cimetière du Père-Lachaise.

Après avoir travaillé en Afrique au NordCameroun, Bernard Juillerat avait choisi de conduire des recherches chez les Yafar de Papouasie Nouvelle-Guinée. Il en rapporta une collection ethnographique très bien documentée pour le musée de l'Homme et rédigea de nombreuses publications dont plusieurs ouvrages sur lité et doté d'un grand sens de l'humour, s'est éteint à l'âge de 91 ans dans sa ville natale de Boston le 22 juin 2004. Il resta soucieux, jusqu'à ses derniers jours, des problèmes des États du Pacifique, fidèle à ses principes d'égalité, d'antiracisme et de justice. Sur le carton d'invitation du Memorial Service organisé en sa mémoire le 19 septembre 2005 à Hagatna, le gouverneur de Guam, Felix P. Camacho, a écrit cette épitaphe éloquente qui résume très bien la vie de Carlton Skinner :

"He was a man of great integrity fighting injustice wherever he found it, wanting everyone to have his chance.»

Merto Theresa, 2004 (20 août). " Skinner, first U.S. civilian governor of Guam, dies », Pacific Daily News.

cette société du Sépik. De 1977 à 1982, Bernard Juillerat appartint au bureau de notre société. Il y participa activement en tant que rédacteur du JSO. Le JSO publiera dans son prochain numéro un hommage retraçant la carrière et l'œuvre de ce grand chercheur.

Divers membres de notre conseil d'administration et de nombreux collègues ayant connu et apprécié Bernard Juillerat se sont prononcés pour l'organisation d'une journée en sa mémoire. Celle-ci pourrait avoir lieu au début de l'année 2007 dans les nouveaux locaux du musée du quai Branly. 